\title{
Cancer, stem cells and cancer stem cells: old ideas, new developments
} Saghi Ghaffari

\author{
Address: Department of Developmental and Regenerative Biology, Department of Medicine, Division of Hematology, Oncology, Black Family \\ Stem Cell Institute, Tisch Cancer Institute, Mount Sinai School of Medicine, New York, NY 10029 \\ Email: saghi.ghaffari@mssm.edu \\ FI000 Medicine Reports 20II, 3:23 (doi:10.3410/M3-23) \\ This is an open-access article distributed under the terms of the Creative Commons Attribution-Non Commercial License \\ (http://creativecommons.org/licenses/by-nc/3.0/legalcode), which permits unrestricted use, distribution, and reproduction in any medium, \\ provided the original work is properly cited. You may not use this work for commercial purposes. \\ The electronic version of this article is the complete one and can be found at: http://f1000.com/reports/m/3/23
}

\begin{abstract}
It has been suggested that, at least in some forms of cancer, a sub-population of slow-cycling, therapyresistant cancer stem cells exists that has the ability to reconstitute the tumor in its entirety. If true, this model implies that conventional therapies based on targeting highly cycling cells within the tumor will leave the slow-cycling stem cell population intact, giving them the opportunity to reinitiate the tumor at a later date. This review discusses the evidence for this model and the likely implications for cancer treatment.
\end{abstract}

Relapse is a sword of Damocles hanging over cancer patients. The removal of the tumor and destruction of its remains do not preclude the potential propagation of the tumor locally or at distance, sometimes even years later, by a few resilient left-over cells. Cancer stem cells have been equated with this sub-population of therapy-resistant cells. The cancer stem cell model posits that a small population of cells within tumors has the ability to perpetuate the tumor in its entirety by giving rise to all its cells. By attributing the "stem cell" label to these cells, the model projects that these cells have appropriated somatic stem cell characteristics, that is cancer stem cells that are mostly dormant or slow-cycling, and are able to regenerate the entire tumor from which they arise. If true, this model implies that conventional therapies based on targeting fast-cycling cells within the tumor will leave the (quiescent or low-cycling) stem cell population intact, giving them the opportunity to reinitiate the tumor at a later date. While the cancer stem cell model has given a ray of hope to patients by reinvigorating cancer research and pointing to new directions for eradicating these life-threatening diseases, it has also stirred much confusion and debate.

\section{Cancer stem cells: hype or reality?}

The decades-old concept of cancer stem cells was awakened from dormancy by John Dick and his colleagues in the 1990s [1-3]. By establishing an in vivo assay using immunocompromised mice whereby one could quantify the number of human blood stem cells in transplanted animals, these investigators identified a small sub-population of human leukemic cells with a self-renewing capacity that could regenerate leukemia in mice. These cells, named leukemia stem cells or leukemiainitiating cells, shared surface markers with normal blood stem cells. The observations led the investigators to conclude that blood stem cells are the target of leukemic transformation. Based on these findings, they proposed that the leukemic clone (like normal blood cells) is organized as a hierarchy, leukemia starting in most immature cells that generate differentiated cells with more restricted functions. A few years later, using various surface markers, several groups identified cells with similar characteristics in several solid tumors, including breast, colon and brain [4-6], that they called cancer stem cells.

Despite these findings, the concept of cancer stem cells and its relevance to the improvement of cancer therapy and survival of cancer patients has been highly debated $[7,8]$. The key question remains as to whether interpreting cancer in the light of cancer stem cell model has an advantage for patients and whether it will increase the chances of curing cancer once for all? The answer is not clear and scientists do not agree. After all, tumors are composed of various chaotic cells that may not derive from a single cell. Tumors may be generated from multiple cancer stem cell clones. Cells that resist treatment may not have any particular 
(stem cell) characteristics other than that they represent the exception to the rule, or happen to be the ones protected by their microenvironment. It has also been proposed that only some but not all cancers follow the cancer stem cell model [8].

\section{What is a stem cell?}

The concept of stem cells itself might provide some answers as to why there is disagreement in the scientific community regarding the value of the cancer stem cell model. The existence of stem cells and their therapeutic use was first demonstrated in blood, making blood stem cells the leading model for stem cell research in other tissues. Likewise it is with blood that the cancer stem cell model is revived.

Stem cells are defined by two fundamental properties. They self-renew, in that every time they divide they give rise to a cell with an identical stem cell program. And they are multipotent, in that they have the capacity to generate all the cells in the tissue they arise from. Stem cells are rare in most adult tissues, and in fact only a few stem cells are sufficient to maintain the entire tissue during a lifetime. Stem cells are mostly dormant, have a low metabolic rate, low growth factor requirement and live a long life. They rarely enter the cell cycle but when they do, for instance in response to cellular loss or damage, they exhibit a tremendous potential to regenerate the entire tissue. These properties insure that these cells stay out of harm's way and protect them from accumulating mutations that may occur during cell divisions. They also have an arsenal of defense mechanisms against chemical and toxic insults and a strong response system against DNA damage as compared with their progeny $[9,10]$. In addition, stem cells live in a defined environment called a stem cell niche with which they interact and which has a significant impact on their fate.

\section{Are all tumor cells equal?}

At the heart of the cancer stem cell concept lies the concept of tumor heterogeneity. Tumors are composed of various cell types, some with tumor-initiating potential, others fast-proliferating or post-mitotic, differentiated and devoid of tumor-regeneration capacity [11]. Tumorigenic cells are genetically unstable, harbor various mutations and are at different stages of development. The cancer stem cell model argues that a few hidden cells within the tumor have stem cell-like properties with higher tumorigenic potential; these cells are able to give rise to all the cells within tumors, resistant to therapy and responsible for recurrence of the disease. Cancer stem cells may be recognized by surface markers and prospectively isolated, assayed for their tumorigenic function and quantified, and ultimately targeted for therapy. Regardless of the cell of origin, cancer follows the stem cell hierarchy, cancer stem cells are responsible for disease progression, undergo epigenetic modifications to give rise to cells with nontumorigenic potential (differentiated cells with more restricted functions) that fill the bulk of the tumor. The premise is that only cancer stem cells cause the tumor and, while other tumor cells may cause symptoms resulting from the bulk of the tumor, only ablation of the cancer stem cells will ultimately eradicate the tumor and prevent its return.

\section{Does cancer start in tissue specific stem cells?} The term "cancer stem cell" has been the subject of much confusion. Oncogenic transformation is the result of accumulation of several genetic hits that ultimately alter cell growth and differentiation. The term "cancer stem cell" suggests that cancer arises from oncogenic transformation of stem cells. Given that stem cells are around for a long time and potentially undergo many divisions in response to demands, they are indeed promising candidates for accumulating a sufficient number of events required for oncogenic transformation. Moreover, the oncogenic process could be more efficient in stem cells as it may borrow from these cells their intrinsic machinery in the regulation of quiescence and resistance to insults (so the oncoprotein does not have to create such mechanisms; mechanisms insuring self-renewal of cancer cells are already in place). Certainly, in the case of chronic myeloid leukemia, the initial event is in a stem cell. However, there are a number of studies published that show that cancer stem cells can be generated by oncogenic transformation of stem cell progeny [12-14]. The type of oncogene may also play a role in determining whether or not stem cells are the target of oncogenic transformation [12].

To make matters worse, "cancer stem cell", and "tumorinitiating cell" (or "leukemia-initiating cell" when it applies) have been used interchangeably, generating another source of confusion.

\section{The quality of the assay}

Another complication is that the definition of cancer stem cells is intertwined with assays that identify these cells. Indeed, the power of the cancer stem cell model is to a large extent limited by the sensitivity of the methodology that is used for measuring the frequency of these cells.

The "cancer stem cell" label evokes the idea that these cells, like adult stem cells, are rare. Quantification of cancer stem cells, as with normal human stem cells, relies heavily on using xenotransplantation models in which human cells are isolated based on their surface markers and injected into immunocompromised mice in which they regenerate the original tumor. This approach is based on several 
assumptions. First, that tissue-specific cancer stem cells can be separated from neighboring normal cells by a given set of surface markers. Since tumors are highly heterogeneous and genomically unstable, proteins expressed on their surface are unlikely to provide a signature of cancer stem cells that is specific to a given tissue or cancer. Indeed, it has been shown in recent studies that some of the most well known surface markers do not necessarily differentiate between tumorigenic and non-tumorigenic cells.

The second assumption is that, once cancer stem cells are injected into mice, they home in on the right tissue where they regenerate the tumor. This presumes that human tumor cells have the proper combinations of proteins to interact with host mouse vessels and tissues. The human cells also have to find the mouse environment hospitable for survival, growth and expansion. It has therefore been suggested that only highly tumorigenic cells would meet these stringent requirements to be detected as cancer stem cells. Also, the degree to which the mice are immunocompromised would also impact the detection of cancer stem cells, using this assay.

Overall, the quality of the assay used is critical in identifying cancer stem cells and it is possible that current results may largely underestimate the true frequency of these cells. This very point was raised by Sean Morrison and colleagues in the case of melanomas. These investigators showed in two consecutive studies that, at least in melanomas, the frequency of tumorigenic cells is very high to the point that distinguishing cancer stem cells from the bulk of the tumor may not matter $[15,16]$. In addition, they showed that, regardless of the stage of the disease, the cells expressing markers that were previously recognized as cancer stem cell-specific can be regenerated from cells categorized as non-tumorigenic [16]. These studies also excluded the possibility that the high frequency with which cancer stem cells are detected in certain malignancies is just an indication of the gravity of the disease as had been suggested previously [17].

It is conceivable, however, that not all cancers follow the cancer stem cell model. And, after all, even cells that are scored as cancer stem cells in assays conducted in mice may not be the ones that are therapy-resistant or the ones that reinitiate the tumor, i.e. relapse or metastasize in humans.

\section{Are cancer stem cells dormant?}

If the therapy-resistant cells are stem cells, they are likely to be, as many somatic stem cells are, mostly dormant. The nature of the current assays for measurements of cancer stem cells precludes the identification of dormant stem cells, since cancer stem cells are identified by their ability to proliferate and generate tumors in the host.
Consequently, direct evidence for quiescence of cancer stem cells has been limited. However, in the case of breast cancer, it is possible to identify tumor cells with the gene signature of normal stem cells [18]. In agreement with this, other studies showed that a nuclear factor, Foxo3a, required for the regulation of normal blood stem cell quiescence $[19,20]$, was found to be essential for maintenance of both mouse and human leukemic stem cells $[21,22]$. Foxo3 with tumor suppressor properties is critical for keeping blood stem cells quiescent and paradoxically is also required for maintaining the leukemic stem cell pool as if the mechanisms that protect quiescence are shared between normal and cancer stem cells.

\section{How does the concept of cancer stem cells affect therapy?}

If cancer stem cells are rare quiescent cells that are responsible for disease progression, then these cells should be targeted along with highly proliferating cells that compose the bulk of the tumor. What is not clear is whether the resistant cells in a cancer are cancer stem cells? Do the non-responding patients have tumors with more cancer stem cells? And what is the impact of current treatments like targeting highly proliferating cells on quiescent cancer stem cells? Is targeting cancer stem cells alone sufficient for shrinking the tumor? Since the cancer stem cell model is highly relevant for recurrence of the cancer, a treatment based on targeting cancer stem cells may be more effective in preventing future relapses but this will need to be assessed in much longer term studies than those reported to date.

The cancer stem cell concept has stimulated lots of interest, engaged many scientists and injected fresh enthusiasm into cancer research. The key challenge is to figure out how to use this model in improving the lives of cancer patients and for that to happen, many fundamental questions need yet to be addressed.

\section{Competing interests}

The author declares that she has no competing interests.

\section{Acknowledgements}

I would like to thank members of my laboratory for helpful discussions.

\section{References}

I. Lapidot T, Pflumio F, Doedens M, Murdoch B, Williams DE, Dick JE: Cytokine stimulation of multilineage hematopoiesis from immature human cells engrafted in SCID mice. Science 1992, 255: | |37-4|.

FI000 factor 6

Evaluated by Saghi Ghaffari 18 Nov 201 I

2. Lapidot T, Sirard C, Vormoor J, Murdoch B, Hoang T, CaceresCortes J, Minden M, Paterson B, Caligiuri MA, Dick JE: A cell 
initiating human acute myeloid leukaemia after transplantation into SCID mice. Nature 1994, 367:645-8.

FI000 factor 6

Evaluated by Saghi Ghaffari 18 Nov 201 I

3. Bonnet $D$, Dick JE: Human acute myeloid leukemia is organized as a hierarchy that originates from a primitive hematopoietic cell. Nat Med 1997, 7:730-7.

FI000 factor 6

Evaluated by Saghi Ghaffari 18 Nov 2011

4. Al-Hajj M, Wicha MS, Benito-Hernandez A, Morrison SJ, Clarke MF: Prospective identification of tumorigenic breast cancer cells. Proc Natl Acad Sci U S A 2003, 100:3983-8.

FI000 factor 9

Evaluated by Saghi Ghaffari 18 Nov 20II, Therese Sørlie 09 Feb 2006

5. Singh SK, Hawkins C, Clarke ID, Squire JA, Bayani J, Hide T, Henkelman RM, Cusimano MD, Dirks PB: Identification of human brain tumour initiating cells. Nature 2004, 432:396-40I.

FI000 factor 6

Evaluated by Saghi Ghaffari 18 Nov 2011

6. O'Brien CA, Pollett A, Gallinger S, Dick JE: A human colon cancer cell capable of initiating tumour growth in immunodeficient mice. Nature 2007, 445:106-10.

FI000 factor 6

Evaluated by Saghi Ghaffari 18 Nov 2011

7. Kelly PN, Dakic A, Adams JM, Nutt SL, Strasser A: Tumor growth need not be driven by rare cancer stem cells. Science 2007 , 317:37.

FI000 factor 15

Evaluated by Monica Justice 21 Nov 2007, Kenneth Zaret 30 Oct 2007, Scott W Lowe 26 Oct 2007, Brent Cochran 21 Sep 2007 Astar Winoto 21 Sep 2007

8. Shackleton M, Quintana E, Fearon ER, Morrison SJ: Heterogeneity in cancer: cancer stem cells versus clonal evolution. Cell 2009, 138:822-9.

9. Mohrin M, Bourke E, Alexander D, Warr MR, Barry-Holson K, Le Beau MM, Morrison CG, Passegué E: Hematopoietic stem cell quiescence promotes error-prone DNA repair and mutagenesis. Cell Stem Cell 20I0, 7:174-85.

FI000 factor 6

Evaluated by Saghi Ghaffari 18 Nov 2011

10. Viale A, De Franco F, Orleth A, Cambiaghi V, Giuliani V, Bossi D, Ronchini C, Ronzoni S, Muradore I, Monestiroli S, Gobbi A, Alcalay M, Minucci S, Pelicci PG: Cell-cycle restriction limits DNA damage and maintains self-renewal of leukaemia stem cells. Nature 2009, 457:5I-6.

FI000 factor 9

Evaluated by Saghi Ghaffari 18 Nov 20II, Matthew J Boyer and Tao Cheng II Feb 2009

II. Visvader JE: Cells of origin in cancer. Nature 20II, 469:3 I4-322.

12. Huntly BJ, Shigematsu H, Deguchi K, Lee BH, Mizuno S, Duclos N, Rowan R, Amaral S, Curley D, Williams IR, Akashi K, Gilliland DG: MOZ-TIF2, but not BCR-ABL, confers properties of leukemic stem cells to committed murine hematopoietic progenitors. Cancer Cell 2004, 6:587-96.

FI000 factor 6

Evaluated by Saghi Ghaffari 18 Nov 2011

13. Krivtsov AV, Twomey D, Feng Z, Stubbs MC, Wang Y, Faber J, Levine JE, Wang J, Hahn WC, Gilliland DG, Golub TR, Armstrong SA:
Transformation from committed progenitor to leukaemia stem cell initiated by MLL-AF9. Nature 2006, 442:818-22.

FI000 factor 10

Evaluated by Saghi Ghaffari 18 Nov 201I, Hector Mayani 23 Nov 2006, Anthony D Ho 26 Sep 2006

14. Goardon N, Marchi E, Atzberger A, Quek L, Schuh A, Soneji S, Woll P, Mead A, Alford KA, Rout R, Chaudhury S, Gilkes A, Knapper S, Beldjord K, Begum S, Rose S, Geddes N, Griffiths M, Standen G, Sternberg A, Cavenagh J, Hunter H, Bowen D, Killick S, Robinson L, Price A, Macintyre E, Virgo P, Burnett A, Craddock C, et al.: Coexistence of LMPP-like and GMP-like leukemia stem cells in acute myeloid leukemia. Cancer Cell 20II, 19:138-52.

FI000 factor 6

Evaluated by Saghi Ghaffari 18 Nov 2011

15. Quintana E, Shackleton M, Sabel MS, Fullen DR, Johnson TM, Morrison SJ: Efficient tumour formation by single human melanoma cells. Nature 2008, 456:593-8.

FI000 factor 16

Evaluated by Saghi Ghaffari 18 Nov 2011, Angelo Cardoso 03 Jul 2009, Tura Camilli and Ashani Weeraratna 20 Feb 2009, Ruth Keri 02 Jan 2009

16. Quintana E, Shackleton M, Foster HR, Fullen DR, Sabel MS, Johnson TM, Morrison SJ: Phenotypic heterogeneity among tumorigenic melanoma cells from patients that is reversible and not hierarchically organized. Cancer Cell 2010, 18:510-23.

FI000 factor 6

Evaluated by Saghi Ghaffari 18 Nov 2011

17. Jordan CT: Cancer stem cells: controversial or just misunderstood? Cell Stem Cell 2009, 4:203-5.

18. Pece S, Tosoni D, Confalonieri S, Mazzarol G, Vecchi M, Ronzoni S, Bernard L, Viale G, Pelicci PG, Di Fiore PP: Biological and molecular heterogeneity of breast cancers correlates with their cancer stem cell content. Cell 2010, I40:62-73.

FI000 factor 7

Evaluated by Saghi Ghaffari 18 Nov 2011, Ruth Keri 24 Mar 2010

19. Miyamoto K, Araki KY, Naka K, Arai F, Takubo K, Yamazaki S, Matsuoka S, Miyamoto T, Ito K, Ohmura M, Chen C, Hosokawa K, Nakauchi H, Nakayama K, Nakayama KI, Harada M, Motoyama N, Suda T, Hirao A: Foxo3a is essential for maintenance of the hematopoietic stem cell pool. Cell Stem Cell 2007, I:I0I-I2.

FI000 factor 7

Evaluated by Saghi Ghaffari I8 Nov 201I

20. Yalcin S, Zhang $X$, Luciano JP, Mungamuri SK, Marinkovic D, Vercherat C, Sarkar A, Grisotto M, Taneja R, Ghaffari S: Foxo3 Is Essential for the Regulation of Ataxia Telangiectasia Mutated and Oxidative Stress-mediated Homeostasis of Hematopoietic Stem Cells. J Biol Chem 2008, 283:25692-25705.

21. Naka K, Hoshii T, Muraguchi T, Tadokoro Y, Ooshio T, Kondo Y, Nakao S, Motoyama N, Hirao A: TGF-beta-FOXO signalling maintains leukaemia-initiating cells in chronic myeloid leukaemia. Nature 2010, 463:676-80.

FI000 factor 10

Evaluated by Saghi Ghaffari 31 Mar 2010, Lilian Varricchio and Anna Migliaccio I5 Mar 2010

22. Helgason GV, Young GA, Holyoake TL: Targeting chronic myeloid leukemia stem cells. Curr Hematol Malig Rep 2010, 5:8I-7.

FI000 factor 6

Evaluated by Saghi Ghaffari 22 Nov 2011 